\title{
Problem Gambling and Problem Gaming in Elite Athletes: a Literature Review
}

\author{
Anders Håkansson ${ }^{1,2,3}$ (1) $\cdot$ N. Durand-Bush ${ }^{4,5} \cdot$ G. Kenttä4,6,7
}

Accepted: 11 October 2021

(c) The Author(s) 2021

\begin{abstract}
Researchers have raised concerns about mental health in elite athletes, including problem gambling, where research hitherto is scarce. While gambling has been assessed in the younger student-athlete population, neither gambling nor the recently recognized behavioral addiction of gaming disorder has been sufficiently addressed in the elite athlete population. The present systematic literature review aimed to summarize research knowledge on the prevalence and correlates of problem gambling and problem gaming in elite athletes. Research papers were searched systematically using the Scopus, PsycINFO, and PubMed/ MEDLINE databases and evaluated following a PRISMA paradigm. For the elite athlete population, eight reports on problem gambling and one report on problem gaming were found. While at least five papers indicated an increased risk of problem gambling in elite athletes compared to the general population, one study from Australia indicated the opposite. Problem gambling was generally more common in male athletes. Knowledge of problem gaming prevalence is thus far limited. It is concluded that increased research in problem gambling and problem gaming in elite athletes is warranted.
\end{abstract}

Keywords Elite athlete $\cdot$ Gambling disorder $\cdot$ Gaming disorder $\cdot$ Behavioral addiction

Mental health in high-performance athletes is a growing concern and has been highlighted by researchers during the past decade (Reardon \& Factor, 2010; Reardon et al., 2019; Rice et al., 2016; Schinke et al., 2018). Overall, mental health in elite athletes may be challenged by contextual factors specific to the world of competitive sports, but it may also be

Anders Håkansson

anders_c.hakansson@med.lu.se

1 Dept. of Clinical Sciences Lund, Psychiatry, Faculty of Medicine, Lund University, Lund, Sweden

2 Clinical Sports and Mental Health Unit, Malmö Addiction Center, Region Skåne, Malmö, Sweden

3 Malmö Addiction Center, Region Skåne, Södra Förstadsgatan 35, plan 4. S-205 02, Malmö, Sweden

4 School of Human Kinetics, University of Ottawa, Ottawa, Canada

5 Canadian Centre for Mental Health and Sport, Orleans, Canada

6 The Swedish School of Sport and Health Sciences, Stockholm, Sweden

7 Swedish Sport Federation, Stockholm, Sweden 
affected by stigma, difficulties in treatment access, and by a risk of athletes being perceived as healthier than they are, due to their great physical capacity and seemingly high degree of personal success and life satisfaction. There has been increasing attention to the need for specialized interventions for elite athletes, such as specific treatment facilities, both due to the characteristics of mental health challenges in athletes and potential gaps in regular or traditional mental health care (Moesch et al., 2018; Van Slingerland et al., 2019).

Although the mental health issues seen in elite athletes and the general population include a broad range of disorders and symptoms, some behavioral addictions have been highlighted as a potential risk for athletes (Reardon et al., 2019; Rice et al., 2016). Among the addictive disorders studied in elite athletes is the gambling disorder. Problem gambling, including the narrower concept of the gambling disorder, is a well-established construct in diagnostic manuals (American Psychiatric Association, 2013; World Health Organization, 2018) and known to affect somewhere between less than $1 \%$ and up to 5-6\% of the general population, across different settings and studies (Calado \& Griffiths, 2016). A gambling disorder has severe consequences on the mental well-being of the affected person, including financial consequences (Reith et al., 2019), high psychiatric comorbidity (Dowling et al., 2015; Håkansson et al., 2018a), suicidal ideation (Ronzitti et al., 2016), and a statistically elevated risk of suicide death (Karlsson \& Håkansson, 2018). Also, given the transfer to an increasing online-based gambling market (Chóliz, 2016), this presents further challenges with respect to increased gambling availability.

Over and above the importance of assessing problem gambling in the general population, gambling may present specific hazards to the elite athlete population. The link between gambling and the world of sports may seem intuitive and can be hazardous in a number of ways. Scholars have raised concerns about attitudes toward gambling among athletes, and the risk of match fixing has received growing attention during the past few years (Frenger et al., 2019), including the risk related to betting on one's own game (Moriconi \& de Cima, 2020). In addition, sport-related contexts are often exposed in gambling advertisements related to sports betting (Deans et al., 2017; Hing et al., 2017; Pitt et al., 2016).

A number of research papers over the past decades have reported gambling and gaming problems among student-athletes, typically college-athletes from the National Collegiate Athletic Association (NCAA) in the USA (Derevensky et al., 2019). However, in line with the increased attention on mental health in elite athletes (Reardon \& Factor, 2010; Reardon et al., 2019; Rice et al., 2016; Schinke et al., 2018), it remains to be fully understood how prevalent problem gambling is among athletes at the elite level. Elite athletes are typically described as athletes in a professional role, or those who compete individually or in teams at a national or international competitive level, such as in the top leagues of team sports (Swann et al., 2015). Elite athletes may be role models for younger athletes and for the general public, and the extent of gambling problems in elite athletes, over and above other health concerns in affected individuals, may also influence attitudes toward gambling in the general population.

The research field of behavioral addictions has expanded, and while gambling disorder so far has represented the only non-substance addictive disorders recognized by diagnostic manuals, problems related to video game behavior have been increasingly highlighted and recently included as a diagnosis in the World Health Organization (2018) diagnostic system (ICD-11), named the gaming disorder. Likewise, few years prior to this, the corresponding disorder (internet gaming disorder) was addressed by the DSM-5 working group and included as a potential diagnosis in need for more research (American Psychiatric Association, 2013). 
The extent of problem gaming in the general population is less established than for problem gambling. A large study in the Norwegian general population described that among individuals with any gaming behavior, $1.4 \%$ were classified as addicted and another $7.3 \%$ were classified as problem gamers (Wittek et al., 2016). Moreover, there is reason to believe that gambling for money and video gaming are behaviors which in many cases are inter-dependent, and problem gambling and problem gaming have been shown to be associated to a certain degree (Karlsson et al., 2019; Wood et al., 2004). Of note, relevant differences have also been identified between clinical patients with gambling disorder and gaming disorder, respectively (Mallorquí-Bagué et al., 2017). Given the novelty of the gaming disorder diagnosis, it is important to research its prevalence in the general population and in specific risk groups. The knowledge about problematic gaming practices among elite athletes are thus far anecdotal rather than based on systematic research data. Media reports have highlighted video gaming as a time-consuming habit in elite soccer players, which could potentially be problematic (Washington Post, 2018, 2020). Time-consuming travelling, for example, may be a factor stimulating increased online behavior including gaming. However, the prevalence and correlates of gaming disorder or problem gaming in elite athletes are largely unknown (Håkansson et al., 2018b).

Altogether, there is need for further research in this area to direct attention to sportspecific contexts and mental health in the population of competitive athletes (Moesch et al., 2018; Van Slingerland et al., 2019). Therefore, the present review aimed to summarize research describing the prevalence and correlates of problem gambling and problem gaming among elite athletes, with an emphasis on research clearly addressing high-performance athletes.

\section{Method}

The present study is a systematic literature review addressing the prevalence of problem gambling or gambling disorder and problem gaming and gaming disorder in elite athletes. The study followed a PRISMA paradigm for the literature search, selection of papers, and interpretation of findings (Figs. 1 and 2). The literature search was carried out by the first author.

\section{Eligibility Criteria}

This systematic review study included papers using the following inclusion criteria: studies identified in the databases listed below which assess the prevalence of problem gambling, gambling disorder, problem gaming, or gaming disorder and which assess individuals specifically described as elite athletes. Papers in English, German, French, Spanish, Italian, or in any of the Scandinavian languages were considered. The literature search was carried out by the first author in July 2021. No restrictions were applied with respect to year of publication. Based on the literature and discussion with the research team, elite athletes were regarded as professional and/or perceived in the paper to represent national teams, top leagues, or a corresponding level (Swann et al., 2015). The major distinction made in the present review was between elite athletes and student-athletes/college-athletes who were in many cases enrolled in studies due to their involvement in the NCAA (Derevensky et al., 




Fig. 1 PRISMA flowchart assessing problem gambling and gambling disorder in athletes. Search words used: problem gambling OR gambling disorder AND athlete

2019). Papers on student-athletes/college-athletes were reviewed with respect to the competitive level of study participants. None of these papers met the inclusion criteria used in the study regarding elite athletes and was therefore excluded from the review. 


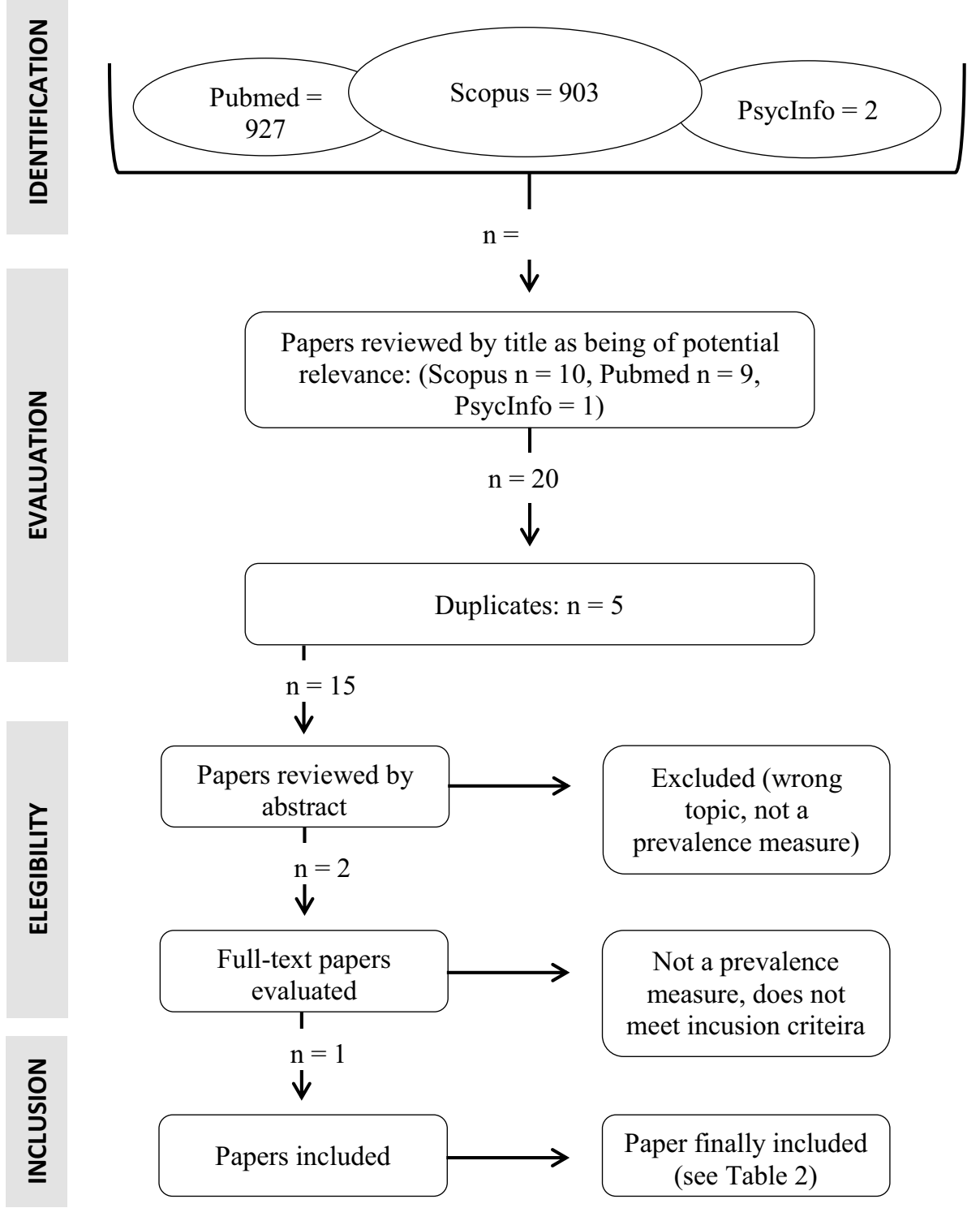

Fig. 2 PRISMA flowchart assessing problem gaming and gaming disorder in athletes. Search words used: problem gaming OR gaming disorder AND athlete

\section{Information Sources and Search Strategy}

The following search strategy was applied within the literature search: the databases Scopus, PsycINFO, and PubMed/MEDLINE were searched for "gambling disorder" OR "problem gambling" AND "athlete" and "gaming disorder" OR "problem gaming" AND "athlete," respectively. In addition, identified review papers were searched for potential 
further papers. In order to conduct a further control search aiming to identify any potentially relevant papers left out in the original searches, a control was carried out in the top relevance findings in the same searches, respectively, on Google Scholar. In addition to the papers identified through this literature search, one paper assessing gambling was identified from a reference list and added in the review.

\section{Selection of Papers and Data Collection Processes}

The results of the literature search are seen in Table 1. A total of 57 papers (including one paper added from a reference list) regarding problem gambling and 24 papers regarding problem gaming were considered, but most papers failed to meet the inclusion criteria. After reading abstracts and-whenever needed-full-text versions, six papers with respect to problem gambling and one paper with respect to problem gaming were judged to fulfill the inclusion criteria. All papers that finally qualified for full-text reading were either in English or German.

\section{Results}

\section{Gambling Disorder and Problem Gambling}

Among the eight papers related to gambling, seven were identified in peer-reviewed scientific journals in English (Grall-Bronnec et al., 2016; Håkansson et al., 2018b, 2020b; Jensen et al., 2019; Pensgaard et al., 2021; Purcell et al., 2020; Vinberg et al., 2020), whereas one publication was a book chapter (Rhind et al., 2014). The years of publication ranged from 2014 to 2021. Three of the studies were from Sweden (Håkansson et al., 2018b, 2020b; Vinberg et al., 2020), one from Australia (Purcell et al., 2020), one from the UK (Rhind et al., 2014), one from France but assessing participants from seven European countries (Grall-Bronnec et al., 2016), one from Sweden and Denmark combined (Jensen et al., 2019), and one from Norway (Pensgaard et al., 2021). One study involved only men (Jensen et al., 2019) and one involved primarily men (Grall-Bronnec et al., 2016), whereas the remaining six included a substantial number of both women and men. Four studies involved a number of different sports (Håkansson et al., 2018b; Pensgaard et al., 2021; Purcell et al., 2020; Rhind et al., 2014), three studies involved a variety of team sports (Grall-Bronnec et al., 2016; Håkansson et al., 2020b; Vinberg et al., 2020), and one study involved only soccer players (Jensen et al., 2019). All eight studies included validated measures of problem gambling (Table 1), and none reported the prevalence of an actual gambling disorder.

In the six studies assessing substantial percentages of participants from both genders, prevalence rates of problem gambling were concluded to be higher in men than in women (Håkansson et al., 2018b, 2020b; Pensgaard et al., 2021; Purcell, et al., 2020; Rhind et al., 2014; Vinberg et al., 2020). In five of the studies (Håkansson et al., 2018b, 2020b; Jensen et al., 2019; Rhind et al., 2014; Vinberg et al., 2020), authors specifically concluded that prevalence rates of problem gambling for men were higher than what would have been expected in the general population, whereas the opposite was seen in the Australian study by Purcell et al (2020). For the UK study (Rhind et al., 2014), it was concluded by the authors that problem gambling was also more common among women athletes than women 


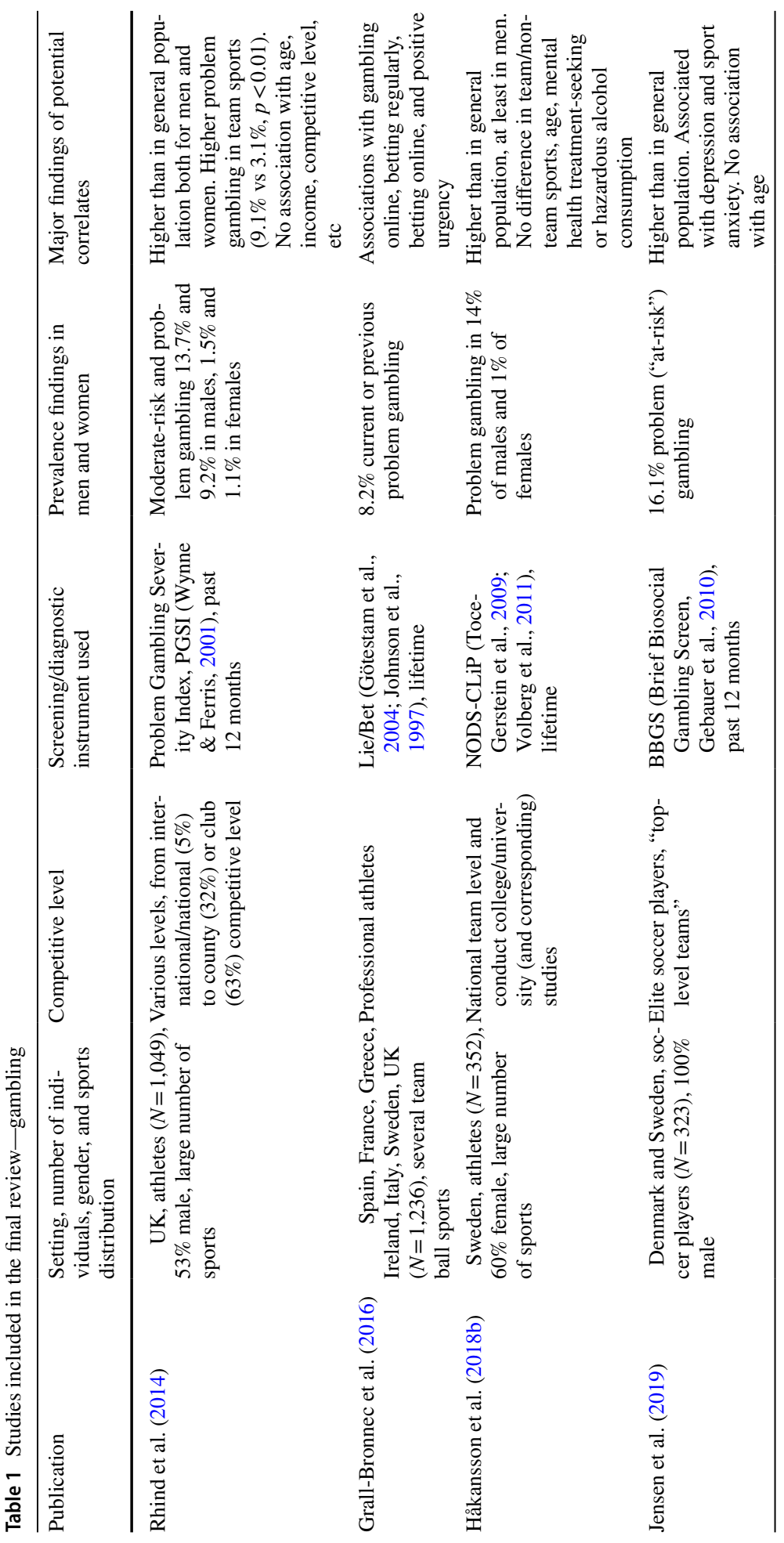




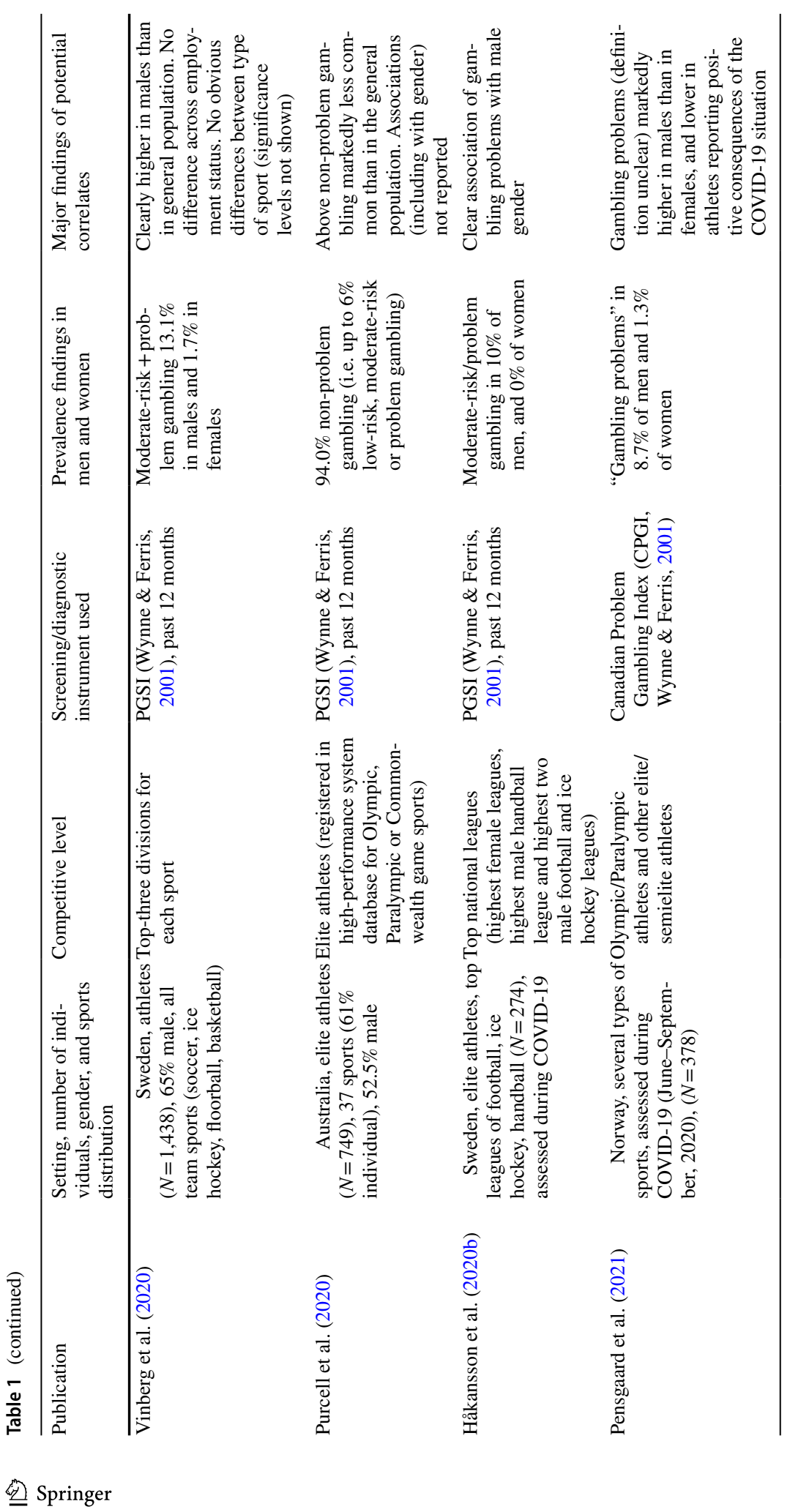


in the general population, while these conclusions appeared less certain in the papers by Håkansson et al. (2018b), Håkansson et al. (2020b), and Vinberg et al (2020).

Three of the studies allowed comparison between different types of sports. In the UK study by Rhind et al. (2014), team sport participants were significantly more likely than individual athletes to be problem gamblers. In contrast, in the study by Håkansson et al., (2018b), no difference was seen between team sport athletes and individual sport athletes. In the Swedish study by Vinberg et al (2020), no statistical comparison across team sports was explicitly stated, but the reported prevalence rates were comparable across ice hockey, soccer, and basketball.

\section{Gaming Disorder and Problem Gaming}

The sole paper addressing problem gaming (but not gaming disorder) was the same publication as one of those assessing problem gambling in elite athletes in Sweden, from a large number of different sports. The study demonstrated that past-6-month problem gaming was seen in $4 \%$ of males and $1 \%$ of females, with a trend toward a significant difference, and problem gaming was significantly associated with problem gambling (Table 2). However, the association between problem gambling and the absolute value of the screening tool used for gaming did not reach statistical significance (Håkansson et al., 2018b).

\section{Discussion}

The present review paper summarized the current knowledge about prevalence rates and correlates of two of the most well-recognized behavioral addictions in elite athlete populations. A limited number of papers in problem gambling were found, and this preliminary body of evidence demonstrated gender differences with problem gambling rates likely to be higher in men. The evidence remains inconclusive as to whether problem gambling in elite athletes is more common than in the general population, and whether the prevalence differs across different sports. Several studies are characterized by a sparsity in the data and possible associations to study. For problem gaming, the literature search indicated a large need for prevalence studies in this population, as only one paper could be found.

\section{Problem Gambling—Preliminary Evidence, Gaps, and Recommendations}

In five of the studies included about problem gambling, authors concluded that the rates of problem gambling detected in each setting are elevated compared to that of the general population (Håkansson et al., 2018b; Jensen et al., 2019; Rhind et al., 2014; Vinberg et al., 2020). In contrast, the findings from elite level athletes in Australia point in the opposite direction. It should be noted that this was reported only as the percentage with no risk gambling (the non-risk category of the four-step classification used from the Problem Gambling Severity Index, Wynne \& Ferris, 2001), that is, without specification of the actual levels of low-risk, moderate-risk, or problem gambling, respectively. However, the difference in non-risk gambling was considerable, such that this paper does not support the overall over-representation of problem gambling in athletes but rather suggests that these associations may vary regionally. Here, more research with scientifically sound assessment, from different geographical regions, is needed, in order to examine whether problematic gambling behaviors are more prevalent in elite athletes. In the general research literature 
Table 2 Studies included in the final review_-gaming

\begin{tabular}{|c|c|c|c|c|c|}
\hline Publication & $\begin{array}{l}\text { Setting, number } \\
\text { of individuals, } \\
\text { gender, and } \\
\text { sports distribu- } \\
\text { tion }\end{array}$ & $\begin{array}{l}\text { Competitive } \\
\text { level }\end{array}$ & $\begin{array}{l}\text { Screening/diag- } \\
\text { nostic instru- } \\
\text { ment used }\end{array}$ & $\begin{array}{l}\text { Prevalence find- } \\
\text { ings in men and } \\
\text { women }\end{array}$ & $\begin{array}{l}\text { Major findings of } \\
\text { potential correlates }\end{array}$ \\
\hline $\begin{array}{l}\text { Håkans- } \\
\text { son et al. } \\
\text { (2018b) }\end{array}$ & $\begin{array}{l}\text { Sweden, athletes } \\
(N=352), 60 \% \\
\text { female, large } \\
\text { number of sports }\end{array}$ & $\begin{array}{l}\text { National team } \\
\text { level, and } \\
\text { conduct } \\
\text { college/ } \\
\text { university (or } \\
\text { correspond- } \\
\text { ing) studies }\end{array}$ & $\begin{array}{l}\text { Gaming Addic- } \\
\text { tion Scale, } \\
\text { GAS (Lem- } \\
\text { mens et al., } \\
2009 \text { ), past } \\
6 \text { months }\end{array}$ & $\begin{array}{l}\text { Problem gaming } \\
\text { in } 4 \% \text { of males } \\
\text { and } 1 \% \text { of } \\
\text { females }\end{array}$ & $\begin{array}{l}\text { Problem gaming sig- } \\
\text { nificantly associ- } \\
\text { ated with problem } \\
\text { gambling }\end{array}$ \\
\hline
\end{tabular}

assessing the prevalence of problem gambling, it has been reported that populations with mental health disorders including substance use disorders are at higher risk of reporting problem gambling or being diagnosed with the disorder (Cowlishaw et al., 2014; Dowling, et al., 2015). Apart from that specific risk group, few prevalence measures of problem gambling in specific sub-groups are available, except the general reporting that prevalence figures differ across continents and nations, and across gender and age groups (Calado \& Griffiths, 2016). Authors have argued that professional occupation (i.e., one's job or livelihood), including a link to the world of sports (Vinberg et al., 2021), may be a risk factor of problem gambling (Binde \& Romild, 2020). However, prevalence figures in other occupations other than that of athletes are few. The differences reported between nations and continents (Calado \& Griffiths, 2016) further indicate the need to repeat prevalence measures in a number of different geographical settings, where the prevalence in the general population can be assumed to differ.

Despite the low number of studies available, the most robust finding-whenever possible to assess from the studies - appeared to be the marked gender difference in problem gambling. The gender differences in problem gambling are well-known from the general population and from clinical populations (Blanco et al., 2006; Calado \& Griffiths, 2016; Ekholm et al., 2014; Håkansson et al., 2017). Whenever data in the present studies were reported for each gender separately (Håkansson et al., 2018b, 2020b; Pensgaard et al., 2021; Rhind et al., 2014; Vinberg et al., 2020), these gender differences were confirmed, and it can even be argued that the difference in problem gambling prevalence between men and women may be larger in athletes than in the general population. In Purcell et al.'s study in Australia, no gender difference was reported, and other studies included only (Jensen et al., 2019) or almost only (Grall-Bronnec et al., 2016) men. Although assessed in a limited number of studies, the rates of problem gambling in female elite athletes may not differ-or may differ little - from that of the general female population (Abbott et al., 2018).

There may be several explanations for the markedly large gender difference in problem gambling in athletes. Although in one study only, a similar finding regarding a surprisingly large gender difference in the prevalence of problem gambling was seen from a web survey addressing people with an assumingly high interest in sports, that is, individuals with regular exercise habits and who were social media followers of well-known fitness profiles (Håkansson et al., 2020a). First, one possible explanation may be the fact that women tend to develop gambling problems at a later age than men, such that the assessment of elite athletes, typically young adults, may not detect women who may or may not develop 
problem gambling later in life, but who have not yet initiated gambling patterns of the same intensity as men. Women have been suggested to have a more rapid evolvement from gambling onset to gambling problems and consistently have shown a higher degree of psychiatric comorbidity in problem gamblers than for their male counterparts (Carneiro et al., 2020; Díez et al., 2014; Granero et al., 2009; Grant et al., 2012; Håkansson et al., 2017; Sundqvist \& Rosendahl, 2019). However, this may occur only at a later stage in life than the period during which an individual is typically involved in elite-level sports.

Also, gambling traditionally has been perceived as a primarily stereotyped "male" activity, and although there has been a "feminization" of the gambling market in recent years, with data indicating a narrowing of the gap in prevalence rates (Abbott et al., 2018; Svensson \& Romild, 2014), there may still be attitudes and perceptions about gambling, which contribute to the marked gender difference within the world of sports. Male sports, typically some of the major team sports attracting massive media attention, generally involve more money and closer ties to the sports betting world than female sports. Professional male athletes usually make more money than women athletes across sports, which can be a contributing factor to men engaging in gambling. It is insufficiently assessed in the literature and beyond the scope of the present study to show how attitudes toward gambling affect gambling rates and problem gambling in men and women in sports. However, men and women may gamble for different reasons (Stark et al., 2012), and the positive link between sport-related settings and gambling may not apply to women to the same extent as they do to men. In future preventive and empirical work, female athletes' gambling may need to be further surveyed, as it cannot be excluded that the increase in female gambling in the general population (Abbott et al., 2018; Svensson \& Romild, 2014) may also affect female athletes over time.

Few studies assessed differences in problem gambling between different types of sports. In the studies by Håkansson et al., (2018b) and by Vinberg et al. (2020), no obvious differences were seen between team sports and non-team sports (Håkansson et al., 2018b), or between each of the team sports assessed in the work by Vinberg et al. (2020). Hypothetically, it could be expected that gambling cultures and betting practices may explain some differences between sports, as some specific sports, particularly a number of team sports, receive a much larger attention from the gambling industry. Indeed, higher problem gambling was seen in team sports in the UK study (Rhind et al., 2014). Thus, data on this question remain inconclusive, and more research in different settings may need to assess the occurrence of problem gambling in different sports. Also, if such differences do exist, they are likely to be influenced both by individual characteristics of the athletes and by factors related to attitudes, cultures, regulation, and betting involvement in sports. Also, for the scientific discussion around this topic, data from other data sources with which one can compare, are largely lacking. A major challenge is likely to be the power problem related to the study of a large range of very diverse sports with different circumstances, level of professional involvement, and various gambling and sponsorship roles. Thus, larger studies are required and should optimally include a number of different countries.

In the studies included here, there was no information about the gambling types reported by the study participants. While included subjects were athletes, the gambling practices measured by problem gambling instruments may not necessarily be associated with their own sport or with any sports betting overall. Betting on one's own game was shown to be associated with problem gambling in the international study by Grall-Bronnec et al. (2016), which is an important finding on which to build, given both the risk of problem gambling in athletes themselves and the risk of match-fixing incidents in the case of gambling on a sporting event that athletes can influence individually. Betting on one's own games or one's 
own sport is known to occur and has been described as a major risk of match-fixing events (Moriconi \& de Cima, 2020). However, it cannot be excluded that gambling in athletes may also involve gambling types distinct from sports, such as chance-based games. While this is beyond the subject of the present study, further studies should be more thorough about outlining gamblers' detailed gambling patterns, and how much their gambling is suspected to be due to institutional factors and attitudes in the specific sport. It is also argued that there is a need for longitudinal and mixed method studies in order to gain a more comprehensive understanding of the development of various types of gambling behavior.

Unfortunately, included studies in this review sparsely assessed association with other types of mental health problems. One of the studies failed to demonstrate an association between problem gambling and treatment sought for mental distress (Håkansson et al., 2018 b), but mental health was suggested as a correlate of problem gambling in this study and other studies as well. Mental health problems are associated with problem gambling in the general population and may present one of the possible explanations of an increased problem gambling prevalence in athletes where this has been found. The extent to which mental health problems contribute to problem gambling in this population and how attitudes and other sport environment-related factors may be contributing to issues remain to be studied. An increased risk of problem gambling in elite athletes can be suspected for a number of reasons, such as (a) the overall exposure of sports in gambling and gambling in sports (Deans et al., 2017; Håkansson \& Widinghoff, 2019; Hing et al., 2017; Pitt et al., 2016), (b) sport sponsorship (Maher et al., 2006), and (c) personality traits common in sports that are likely to contribute to gambling behavior, particularly competitiveness (Harris et al., 2015).

Two of the studies included in the present review were carried out with respect to behavioral changes or changes in mental health in athletes during the COVID-19 pandemic (Håkansson et al., 2020b; Pensgaard et al., 2021). Specifically, the Swedish study was conducted when high-level sports globally were in virtually complete lockdown (Håkansson et al., 2020b), whereas the Norwegian study inclusion period was somewhat longer but still primarily involved the earlier phase of the pandemic (Pensgaard et al., 2021). The specific effects of the COVID-19 pandemic on gambling behaviors are beyond the scope of the present review paper, but both studies clearly demonstrated a gender difference in gambling problems, as in a number of other papers here. In addition, the Swedish study, carried out with a methodology similar to a general population study in the same setting (Håkansson, 2020), concluded that the self-reported changes in gambling behaviors during the pandemic were similar to those reported in the general population, that is, with a limited proportion reporting an increase in gambling, but with a significant link between this and gambling problems (Håkansson et al., 2020a). Given the extensive consequences of the pandemic on the world of sports, including career uncertainty and mental distress (Håkansson et al., 2020b), problem gambling within the group of elite athletes may require further research attention, also with respect to the impact of COVID-19.

\section{Problem Gaming—Preliminary Evidence, Gaps, and Recommendations}

Problem gaming was an area with limited research in elite sport, and only one publication was found. It is difficult to generalize or draw conclusions from this paper, including how problem gaming in elite athletes may relate to the general population. The problem gaming scores reported by Håkansson et al., (2018b) were lower than those from the general 
population web survey carried out in the same geographical setting, although with a general population sample recruited from a market survey company's panel members (Karlsson et al., 2019). Given the sparsity of general population prevalence data in the area, and the lack of studies so far with athletes, it is not possible to hypothesize whether athletes are at higher risk or not. Thus, this calls for research with respect to the prevalence and correlates of problem gaming, both with elite athletes and other populations.

Also, the more detailed habits of gaming among athletes are largely unknown. Recently, media reports highlighted the possible increase in gaming practices by athletes during the COVID-19 pandemic, due to the cancellation of their sport events (Washington Post, 2020). This type of reporting may suggest a role of gaming during spare time, but scientific data in the area is lacking, and gaming habits, as well as problem gaming in elite athletes, need to be researched in the future. While this is a universal research need, lifestyle changes during the COVID-19 pandemic, including in athletes (Håkansson et al., 2020b), may further strengthen the need for research addressing problem gambling among elite athletes.

\section{Limitations}

The present study has limitations. While it attempted to summarize the literature in a sub-group rarely researched, the scope of the findings is clearly limited by the low number of publications identified. This is particularly the case for problem gaming, for which only one study was available. In addition, the latter is also made up of one of the smallest studies identified here. Furthermore, the aim of the paper was to assess elite athletes specifically, as a number of available research publications, including a review paper summarizing them (Derevensky et al., 2019), have primarily assessed populations of student-athletes. Comparing studies that target elite athletes includes a degree of uncertainty with respect to the unconcise definition for competing at an elite level. For example, athletes' living conditions may be differ substantially between a person identified as an elite athlete in a smaller, individual sport, compared to a person belonging to a top division in a large team sport and possibly even with a professional status. Thus, more studies, and larger studies, are needed in order to clearly describe the risk of being a problem gambler, or a problem gamer, in different sub-types of sports, and in different sub-groups of athletes with diverse levels of professional status. Moreover, future studies should aim to include both women and men. Although the majority of studies included in this review could be assessed with respect to gender, two of the studies had included only men (Jensen et al., 2019) or almost only men (Grall-Bronnec et al., 2016). Especially, given the assumingly lower prevalence of problem gambling, or problem gaming, among female athletes, future studies should intend to include a sufficient sample of female participants for these estimates to be valid.

\section{Conclusions}

More research is needed in the area of problem gambling and problem gaming in elite athletes. For problem gaming in particular, research is essentially nonexistent, thus further studies, including comparative studies with the general population, are warranted. 
In problem gambling, some papers indicate a higher prevalence in male elite athletes compared to their female counterparts. However, additional studies are required to confirm this. Also, further research on gambling in different types of sports are needed. In summary, the present review paper calls for increased research in behavioral addictions in elite athletes. Also, given the high comorbidity of addictive behaviors with other mental health disorders, and the fact that such associations were rarely assessed in the studies identified, further research should address this.

Funding Open access funding provided by Lund University.

\section{Declarations}

Conflict of Interest Håkansson receives an overall non-study-specific research support from the state-owned Swedish gambling operator AB Svenska Spel and receives study-specific support for projects and $\mathrm{PhD}$ students from the research council of the same organization, as well as from the research councils of the Swedish alcohol monopoly Systembolaget and the Swedish enforcement authority. Håkansson has also received non-financial study support from a company providing tools for electronic follow-up of clinical patients with gambling disorder, as part of a joint research project. None of these organizations had any role in the present work. Durand-Bush and Kenttä report no conflicts of interest.

Open Access This article is licensed under a Creative Commons Attribution 4.0 International License, which permits use, sharing, adaptation, distribution and reproduction in any medium or format, as long as you give appropriate credit to the original author(s) and the source, provide a link to the Creative Commons licence, and indicate if changes were made. The images or other third party material in this article are included in the article's Creative Commons licence, unless indicated otherwise in a credit line to the material. If material is not included in the article's Creative Commons licence and your intended use is not permitted by statutory regulation or exceeds the permitted use, you will need to obtain permission directly from the copyright holder. To view a copy of this licence, visit http://creativecommons.org/licenses/by/4.0/.

\section{References}

Abbott, M. W., Romild, U., \& Volberg, R. A. (2018). The prevalence, incidence, and gender and agespecific incidence of problem gambling: Results of the Swedish longitudinal gambling study (Swelogs). Addiction, 113, 699-707. https://doi.org/10.1111/add.14083

American Psychiatric Association. (2013). Diagnostic and statistical manual of mental disorders (5th ed.). American Psychiatric Association.

Binde, P., \& Romild, U. (2020). Risk of problem gambling among occupational groups: A population and registry study. Nordic Studies on Alcohol and Drugs, 37, 262-278. https://doi.org/10.1177/ 1455072519899779

Blanco, C., Hasin, D. S., Petry, N., Stinson, F. S., \& Grant, B. F. (2006). Sex differences in subclinical and DSM-IV pathological gambling: Results from the National Epidemiologic Survey on Alcohol and Related Conditions. Psychological Medicine, 36, 943-953. https://doi.org/10.1017/S0033 291706007410

Calado, F., \& Griffiths, M. (2016). Problem gambling worldwide: An update and systematic review of empirical research (2000-2015). Journal of Behavioral Addiction, 5, 592-613. https://doi.org/10. $1556 / 2006.5 .2016 .073$

Carneiro, E., Tavares, H., Sanches, M., Pinsky, I., Caetano, R., Zaleski, M., \& Laranjeira, R. (2020). Gender differences in gambling exposure and at-risk gambling behavior. Journal of Gambling Studies, 36, 445-457. https://doi.org/10.1007/s10899-019-09884-7

Chóliz, M. (2016). The challenge of online gambling: The effect of legalization on the increase in online gambling addiction. Journal of Gambling Studies, 32, 749-756. https://doi.org/10.1007/ s10899-015-9558-6 
Cowlishaw, S., Merkouris, S., Chapman, A., \& Radermacher, H. (2014). Pathological and problem gambling in substance use treatment: A systematic review and meta-analysis. Journal of Substance Abuse Treatment, 46, 98-105. https://doi.org/10.1016/j.jsat.2013.08.019

Deans, E. G., Thomas, S. L., Derevensky, J., \& Daube, M. (2017). The influence of marketing on the sports betting attitudes and consumption behaviours of young men: Implications for harm reduction and prevention strategies. Harm Reduction Journal, 14, 5. https://doi.org/10.1186/ s12954-017-0131-8

Derevensky, J. L., McDuff, D., Reardon, C. L., Hainline, B., Hitchcock, M. E., \& Richard, J. (2019). Problem gambling and associated mental health concerns in elite athletes: A narrative review. British Journal of Sports Medicine, 53, 761-766. https://doi.org/10.1136/bjsports-2019-100668

Díez, D., Aragay, N., Soms, M., Prat, G., \& Casas, M. (2014). Male and female pathological gamblers: Bet in a different way and show different mental disorders. The Spanish Journal of Psychology, 17, E101. https://doi.org/10.1017/sjp.2014.88

Dowling, N. A., Cowlishaw, S., Jackson, A. C., Merkouris, S. S., Francis, K. L., \& Christensen, D. R. (2015). Prevalence of psychiatric co-morbidity in treatment-seeking problem gamblers: A systematic review and meta-analysis. Australian and New Zealand Journal of Psychiatry, 49, 519-539. https://doi.org/10.1521/pedi_2014_28_168

Ekholm, O., Eiberg, S., Davidsen, M., Holst, M., Larsen, C. V., \& Juel, K. (2014). The prevalence of problem gambling in Denmark in 2005 and 2010: A sociodemographic and socioeconomic characterization. Journal of Gambling Studies, 30, 1-10. https://doi.org/10.1007/s10899-012-9347-4

Frenger, M., Emrich, E., \& Pitsch, W. (2019). Corruption in Olympic sports: Prevalence estimations of match fixing among German squad athletes. SAGE Open, 1-13. https://doi.org/10.1177/2158244019 865361

Gebauer, L., LaBrie, R., \& Shaffer, H. J. (2010). Optimizing DSM-IV-TR classification accuracy: A brief biosocial screen for detecting current gambling disorders among gamblers in the general household population. Canadian Journal of Psychiatry, 55, 82-90. https://doi.org/10.1177/07067 4371005500204

Götestam, K. G., Johansson, A., Wenzel, H. G., \& Simonsen, I. E. (2004). Validation of the lie/bet screen for pathological gambling on two normal population data sets. Psychological Reports, 95(3 Pt 1), 1009-1013. https://doi.org/10.2466/pr0.95.3.1009-1013

Grall-Bronnec, M., Caillon, J., Humeau, E., Perrot, B., Remaud, M., Guilleux, A., Rocher, B., Sauvaget, A., \& Bouju, G. (2016). Gambling among European professional athletes. Prevalence and associated factors. Journal of Addictive Diseases, 35, 278-290. https://doi.org/10.1080/10550887.2016.1177807

Granero, R., Penelo, E., Martínez-Giménez, R., Alvarez-Moya, E., Gómez-Pena, M., Aymamí, N., Bueno, B., Fernández-Aranda, F., \& Jiménez-Murcia, S. (2009). Sex differences among treatment-seeking adult pathological gamblers. Comprehensive Psychiatry, 50, 173-180. https://doi.org/10.1016/j.compp sych.2008.07.005

Grant, J. E., Odlaug, B. L., \& Mooney, M. E. (2012). Telescoping phenomenon in pathological gambling: Association with gender and comorbidities. Journal of Nervous and Mental Disorders, 200, 996-998. https://doi.org/10.1097/NMD.0b013e3182718a4d

Håkansson, A. (2020). Changes in gambling behavior during the COVID-19 pandemic - A web survey study in Sweden. International Journal of Environment Research and Public Health, 17, 4013. https:// doi.org/10.3390/ijerph17114013

Håkansson, A., Entezarjou, A., Kenttä, G., Fernández-Aranda, F., Jiménez-Murcia, S., \& Gunnarsson, B. (2020a). Problem gambling in the fitness world - A general population web survey. International Journal of Environment Research and Public Health, 17, 1342. https://doi.org/10.3390/ijerph17041342

Håkansson, A., Jönsson, C., \& Kenttä, G. (2020b). Psychological distress and problem gambling in elite athletes during COVID-19 restrictions - A web survey in top leagues of three sports during the pandemic. International Journal of Environment Research and Public Health, 17, 6693. https://doi.org/10. 3390/ijerph17186693

Håkansson, A., Karlsson, A., \& Widinghoff, C. (2018a). Primary and secondary diagnoses of gambling disorder and psychiatric comorbidity in the Swedish health care system - A Nationwide Register Study. Frontiers in Psychiatry, 9, 426. https://doi.org/10.3389/fpsyt.2018.00426

Håkansson, A., Kenttä, G., \& Åkesdotter, C. (2018b). Problem gambling and gaming in elite athletes. Addictive Behaviors Reports, 8, 79-84. https://doi.org/10.1016/j.abrep.2018.08.003

Håkansson, A., Mårdhed, E., \& Zaar, M. (2017). Who seeks treatment when medicine opens the door to gambling disorder patients - Psychiatric co-morbidity and heavy predominance of online gambling. Front Psychiatry, 8, 255. https://doi.org/10.3389/fpsyt.2017.00255 
Håkansson, A., \& Widinghoff, C. (2019). Television gambling advertisements: Extent and content of gambling advertisements with a focus on potential high-risk commercial messages. Addictive Behaviors Reports, 9, 100182. https://doi.org/10.1016/j.abrep.2019.100182

Harris, N., Newby, J., \& Klein, R. G. (2015). Competitiveness facets and sensation seeking as predictors of problem gambling among a sample of university student gamblers. Journal of Gambling Studies, 31, 385-396. https://doi.org/10.1007/s10899-013-9431-4

Hing, N., Russell, A. M. T., Lamont, M., \& Vitartas, P. (2017). Bet anywhere, anytime: An analysis of internet sports bettors' responses to gambling promotions during sports broadcasts by problem gambling severity. Journal of Gambling Studies, 33, 1051-1065. https://doi.org/10.1007/s10899-017-9671-9

Jensen, S. N., Ivarsson, A., Fallby, J., \& Elbe, A. M. (2019). Gambling behaviors among Danish and Swedish elite football players. Journal of Clinical Sport Psychology, 13, 95-102. https://doi.org/10.1123/ jcsp.2017-0021

Johnson, E. E., Hamer, R., Nora, R. M., Tan, B., Eisenstein, N., \& Engelhart, C. (1997). The Lie/Bet questionnaire for screening pathological gamblers. Psychological Reports, 80, 83-88. https://doi.org/10. 2466/pr0.1997.80.1.83

Karlsson, A., \& Håkansson, A. (2018). Gambling disorder, increased mortality, suicidality, and associated comorbidity: A longitudinal nationwide register study. Journal of Behavioral Addictions, 7, 10911099. https://doi.org/10.1556/2006.7.2018.112

Karlsson, J., Broman, N., \& Håkansson, A. (2019). Associations between problematic gambling, gaming, and internet use: A cross-sectional population survey. Journal of Addiction, 2019, 1464858. https://doi. org/10.1155/2019/1464858

Lemmens, S. J., Valkenburg, M. P., \& Peter, J. (2009). Development and validation of a game addiction scale for adolescents. Media Psychology, 12, 77-95. https://doi.org/10.1080/15213260802669458

Maher, A., Wilson, N., Signal, L., \& Thomson, G. (2006). Patterns of sports sponsorship by gambling, alcohol and food companies: An Internet survey. BMC Public Health, 6, 95. https://doi.org/10.1186/ 1471-2458-6-95

Mallorquí-Bagué, N., Fernández-Aranda, F., Lozano-Madrid, M., Roser, G., Mestre-Bach, G., Baño, M., Pino-Gutiérrez, A. D., Gómez-Peña, M., Aymamí, N., Menchón, J. M., \& Jiménez-Murcia, S. (2017). Internet gaming disorder and online gambling disorder: Clinical and personality correlates. Journal of Behavioral Addictions, 6, 669-677.

Moesch, K., Kenttä, G., Kleinert, J., Quignon-Fleuret, C., Cecil, S., \& Bertollo, M. (2018). FEPSAC position statement: Mental health disorders in elite athletes and models of service provision. Psychology of Sport and Exercise, 38, 61-71. https://doi.org/10.1016/j.psychsport.2018.05.013

Moriconi, M., \& de Cima, C. (2020). Betting practices among players in Portuguese championships: From cultural to illegal behaviours. Journal of Gambling Studies, 36, 161-181. https://doi.org/10.1007/ s10899-019-09880-X

Pensgaard, A. M., Oevreboe, T. H., \& Ivarsson, A. (2021). Mental health among elite athletes in Norway during a selected period of the COVID-19 pandemic. BMJ Open Sport \& Exercise Medicine, 7, e001025. https://doi.org/10.1136/bmjsem-2020-001025

Pitt, H., Thomas, S. L., Bestman, A., Stoneham, M., \& Daube, M. (2016). "It's just everywhere!" Children and parents discuss the marketing of sport wagering in Australia. Australian and New Zealand Journal of Psychiatry, 40, 480-486. https://doi.org/10.1111/1753-6405.12564

Purcell, R., Rice, S., Butterworth, M., \& Clements, M. (2020). Rates and correlates of mental health symptoms in currently competing elite athletes from the Australian national high-performance sports system. Sports Medicine. https://doi.org/10.1007/s40279-020-01266-z.

Reardon, C. L., \& Factor, R. M. (2010). A systematic review of diagnosis and medical treatment of mental illness in athletes. Sports Medicine, 40, 961-980. https://doi.org/10.2165/11536580-000000000-00000

Reardon, C. L., Hainline, B., Aron, C. M., Baron, D., Baum, A. L., Bindra, A., Budgett, R., Campriani, N., Castaldelli-Maia, J. M., Currie, A., Derevensky, J. L., Glick, I. D., Gorczynski, P., Gouttebarge, V., Grandner, M. A., Han, D. H., McDuff, D., Mountjoy, M., Polat, A., ... Engebretsen, L. (2019). Mental health in elite athletes: International Olympic Committee consensus statement. British Journal of Sports Medicine, 53, 667-699. https://doi.org/10.1136/bjsports-2019-100715

Reith, G., Wardle, H., \& Gilmore, I. (2019). Gambling harm: A global problem requiring global solutions. Lancet, 394, 1212-1214. https://doi.org/10.1016/S0140-6736(19)31991-9

Rhind, D. J. A., O'Brien, K., Jowett, S., \& Greenless, I. (2014). Problem gambling among athletes in the United Kingdom. In F. Gobet \& M. Schiller (Eds.), Problem gambling: Cognition, prevention and treatment (pp. 127-139). Palgrave Macmillan.

Rice, S. M., Purcell, R., De Silva, S., Mawren, D., McGorry, P. D., \& Parker, A. G. (2016). The mental health of elite athletes: A narrative systematic review. Sports Medicine, 46, 1333-1353. https://doi.org/ 10.1007/s40279-016-0492-2 
Ronzitti, S., Lutri, V., Smith, N., Clerici, M., \& Bowden-Jones, H. (2016). Gender differences in treatmentseeking British pathological gamblers. Journal of Behavioral Addictions, 5, 231-238. https://doi.org/ 10.1556/2006.5.2016.032

Schinke, R. J., Stambulova, N. B., Si, G., \& Moore, Z. (2018). International society of sport psychology position stand: Athletes' mental health, performance, and development. International Journal of Sport \& Exercise Psychology, 16, 622-639. https://doi.org/10.1080/1612197X.2017.1295557

Stark, S., Zahlan, N., Albanese, P., \& Tepperman, L. (2012). Beyond description: Understanding gender differences in problem gambling. Journal of Behavioral Addictions, 1, 123-134. https://doi.org/10.1556/ JBA.1.2012.3.5

Sundqvist, K., \& Rosendahl, I. (2019). Problem gambling and psychiatric comorbidity-risk and temporal sequencing among women and men: Results from the Swelogs case-control study. Journal of Gambling Studies, 35, 757-771. https://doi.org/10.1007/s10899-019-09851-2

Svensson, J., \& Romild, U. (2014). Problem gambling features and gendered gambling domains amongst regular gamblers in a Swedish population-based study. Sex Roles, 70, 240-254. https://doi.org/10. 1007/s11199-014-0354-Z

Swann, C., Moran, A., \& Piggott, D. (2015). Defining elite athletes: Issues in the study of expert performance in sport psychology. Psychology of Sport and Exercise, 16(P1), 3-14. https://doi.org/10.1016/j. psychsport.2014.07.004

Toce-Gerstein, M., Gerstein, R. D., \& Volberg, A. R. (2009). The NODS-CLiP: A rapid screen for adult pathological and problem gambling. Journal of Gambling Studies, 25, 541-555. https://doi.org/10. 1007/s10899-009-9135-y

Van Slingerland, K. J., Durand-Bush, N., Bradley, L., Goldfield, G., Archambault, R., Smith, D., Edwards, C., Delenardo, S., Taylor, S., Werthner, P., \& Kenttä, G. (2019). Canadian Centre for Mental Health and Sport (CCMHS) position statement: Principles of mental health in competitive and high-performance sport. Clinical Journal of Sports Medicine, 29, 173-180. https://doi.org/10.1097/JSM.00000 00000000665

Vinberg, M., Durbeej, N., \& Rosendahl, I. (2020). Gambling and gambling problem among elite athletes and their professional coaches: Findings from a Swedish total population survey of participants in four sports. International Gambling Studies, 20, 262-281. https://doi.org/10.1080/14459795.2020.1726990

Vinberg, M., Wetterborg, D., \& Enebrink, P. (2021). Gambling at work: A qualitative study of Swedish elite athletes, coaches, and managers. Journal of Gambling Studies. https://doi.org/10.1007/ s10899-021-10007-4.

Volberg, R. A., Munck, I. M., \& Petry, N. M. (2011). A quick and simple screening method for pathological and problem gamblers in addiction programs and practices. American Journal on Addictions, 20, 220-227. https://doi.org/10.1111/j.1521-0391.2011.00118.x

Washington Post. (2018). Are pro athletes playing too much Fortnite? Some teams are worried. Retrieved 2020 June 26 from https://www.washingtonpost.com/sports/are-pro-athletes-playing-too-much-fortn ite-some-teams-are-worried/2018/07/20/664d5ffe-8ab5-11e8-85ae-511bc1146b0b_story.html\%20Acc essed $\% 20$ June $\% 2026$.

Washington Post. (2020). From courts to consoles: With live sports canceled, pro athletes join the streaming surge. Retrieved 2020 June 26 from https://www.washingtonpost.com/video-games/esports/2020/03/ 30/athletes-streaming-twitch-video-games-coronavirus/.

Wittek, C. T., Finserås, T. R., Pallesen, S., Mentzoni, R. A., Hanss, D., Griffiths, M. D., \& Molde, H. (2016). Prevalence and predictors of video game addiction: A study based on a national representative sample of gamers. International Journal of Mental Health and Addiction, 14, 672-686. https://doi.org/ 10.1007/s11469-015-9592-8

Wood, R. T. A., Gupta, R., Derevensky, J. L., \& Griffiths, M. (2004). Video game playing and gambling in adolescents: Common risk factors. Journal of Child and Adolescent Substance Abuse, 14, 77-100.

World Health Organization. (2018). Gaming Disorder. Retrieved 2020 June 26 from http://www.who.int/ features/qa/gaming-disorder/en/.

Wynne, H., \& Ferris, J. (2001). The Canadian Problem Gambling Index: Final report. Canadian Centre on Substance Abuse.

Publisher's Note Springer Nature remains neutral with regard to jurisdictional claims in published maps and institutional affiliations. 